\title{
EL UNIVERSO MÁGICO DE NERVAL EN AURÉLIA
}

Maria J. Pérez Winter de Tamburini

Aurélia (1855), el poema en prosa de Nerval, es la expansión del sueño en la vida real, como lo afirma Jean Giraudoux. Y no olvidemos que la esencia de lo fantástico reside, en todo caso, en un cierto clima en el que, sutilmente, sueño y realidad se interpenetran hasta el punto de que toda línea de demarcación desaparece.

Raramente -continúa Giraudoux- un poeta ha sabido ubicarse con esta justeza sobre la linea que separa el mundo real del mundo interior y adosarse en medio de tanto sol contra un muro iluminado de luz infernal.

\section{LAS FUENTES DE AURÉLIA}

El carácter insólito del libro, el hecho que Aurélia traduce, expone una experiencia, por naturaleza única $\Theta$ irremplazable, es suficiente para descorazonar a todos aquellos que quieran, a cualquier precio, encontrar las "fuentes" de un texto literario. Por lo tanto Nerval, lector enciclopédico, se adapta a una tradición y aún la sobrepasa y la trasciende.

Nuestro autor fue nutrido profundamente por el s. XVIII, $y$ en particular por toda una corriente de ocultismo y de iluminismo.

Fue también, el primer "inventor" de Réstif de la Bretonne; le consagra un estudio en Les llluminées que es más revelador de Nerval que lo que aclara sobre Réstif.

Más cerca del poeta, podemos citar a Nodier, que nuestro autor siempre consideró como un "tutor espiritual" y del cual su cuento Une heure ou la visión, entre otros cuentos fantásticos, le mostraron el camino a seguir.

Alemania también tuvo sobre su imaginación una importancia que sobrepasa a aquella de un simple contacto intelectual. Alemania es, para $6 \mathrm{l}$, el pais de la madre. Es allá, en un pequeno cementerio de Silesia, donde reposa aquella que no conoció pero cuya imagen lo visita a menudo y con la que Aurélia se confunde a menudo: Es la Muerte - o la Muerta, dice. 
Por otra parte, Nerval redactó, en parte, su Aurélia durante su último viaje a Alemania.

Fausto de Goethe, cuyo prefacio y traducción al francés los hizo él, es también como Aurélia un descenso a los infiernos. Hoffman y el cuento fantástico alemán están a la moda.

Estas son algunas de las fuentes más directas, tanto francesas como alemanas, que tuvo nuestro poeta.

Pero otros relatos tienen también un papel importante en la elaboración de la obra: El asno de oro de Apuleyo, que el autor lo tiene presente, en particular en el capltulo que relata la aparición de Isis. Porque Aurélia es también Isis. $Y$ una sintesis de todas las mujeres que el poeta amó: su madre y Jenny Colon, en primer lugar y luego otras mujeres reales o ideales: Laura y Beatriz, la Virgen Maria. Pero ella, también, es la virgen de los dolores, la mujer abandonada en el diluvio, la mujer cuyo grito resonó.

En cuanto a los detalles de tal o cual visión, o tal dato sobre la historia de las religiones, sobre el Oriente, etc., Nerval los tomó de las innumerables obras que habia, quizás, comenzado a leer desde la infancia, en casa de su tio, ese tío que le dijo: Dios, es el sol.

Mis libros, montón raro de la ciencia de todos los tiempos, historia viajes, religiones, cábala, astrología, convocaron las sombras de Pico de la Mirandola, del sabio Mersius, de Nicolás de Cusa, afirma Nerval en el capítulo VI de la Segunda Parte de su libro. Y en el capitulo I de la Primera Parte, recuerda a los grandes visionarios que, antes que él, exploraron las tinieblas: el citado Apuleyo, Dante, Swendenborg.

\section{ORIGINALIDAD DE AURÉLIA}

Pero de este "montón extravagante" , nuestro autor hizo una obra que tiene su coherencia propia, su ritmo. Todas las "fuentes" se encuentran fundidas en el solo crisol de la elaboración estética. Eso que da a Aurélia su originalidad fundamental, es, a la vez, que la obra retrate una experiencia vivida (y dolorosamente vivida porque el descenso a los infiernos de la locura se consuma en el sufrimiento), pero también que ella está compuesta gracias a una extraordinaria facultad de síntesis, de reconstrucción, de organización. Asi Aurélia es toda otra cosa que un cúmulo de referencias sabias; toda otra cosa, también, que el diario de un esquizofrénico. 
Como bien lo explica Plaget: Cuatro procesos fundamentales caracterizan esta revolución intelectual que se cumple durante los dos primeros años de la existencia (refiriéndose a un cierto parentesco entre el mundo del psicótico y el del niño) : éstas son las construcciones de las categorias del objeto y del espacio, de la causalidad y del tiempo. Estas coordenadas fundamentales del espiritu humano se encuentran alteradas en Aurblia: los objetos están en perpetua metamorfosis y la relación de la conciencia y el objeto es desvaída. El espacio es vertiginoso: sueños de colores, de laberintos. La causalidad es perturbadora. No hay azar, todo está determinado y todo tiene un sentido en relación con Nerval. El número de la puerta, una conversación siempre se unen a su propio drama. En fin, el tiempo es tan vertiginoso como el espacio en el suefio nervaliano.

Se puede pensar que sus sueños en Aurélia tienen elementos muy cercanos a las alucinaciones de la esquizofrenia. Pero, si Nerval hubiera estado totalmente loco, no hubiera podido escribir, porque la locura, con la desaparición de la conciencia, no permite una creación literaria que supone, al contrario, un alto grado de conciencia y una capacidad de dominar el desdoblamiento. El hecho de que Nerval pueda hacer hablar a su doble, escribir una escena como aquella del casamiento del doble, es revelador: los suenos de Aurélia son, a la vez, muy próximos y muy diferentes a los de la alucinación enfermiza, totalmente recreados por la voluntad del artista, esta voluntad donde, justamente, la locura no tiene nada que hacer.

Nerval escritor supo crear un universo mítico y mágico en su libro, metamorfoseando alucinaciones y recuerdos por la transmutación artística. La locura ya no es, es el sueño. Y se llega a él por ces portes d'ivoire ou de corme qui nous séparent du monde invisible - pág.3-. (Estas puertas de marfil y de asta que nos separan del mundo invisible.).

Porque su locura fue, también, un don: el don de percibir la Naturaleza como un Vidente. Como el misterioso aleph tan querido por Borges, la locura es ese lugar mistico desde donde uno puede contemplar el universo en su totalidad, a la vez temporal y espacial: todas las épocas, todas las regiones se abrazan con una sola mirada: Comme si les murs de la salle se fussent ouverts sur des perspectives infinies, il me semblait voir une chaîne non interrompue d'hommes et de femmes en qui fótais et qui étaient moi-meme; les costumes de tous les peuples, les images de tous les pays apparaissaient distinctement a la fois, comme si mes facultés d'attention s'étaient multipliées sans se confondre, par un phénomène d'espace analogue à celul du temps qui concentro un sièclo d'action dans une minute de reve.- pág. 19/20. (Como si las paredes del salón se abriesen a perspectivas infinitas, me pareció ver una ininterrumpida cadena de hombres y de mujeres en cuyo espinitu yo existía y que a su vez existian en el mí; los trajes de todos los pueblos, las imágenes de todos los países apareclan simultáneos y distintos, como si las facultades de mi atención se hubiesen multiplicado sin confundirse, por un fenómeno del espacio semejante al del tiempo, que logra concentrar un siglo de acción en un minuto de suefo.). 
Todo palpitante, todo se corresponde, todo tiene sentido. La imaginación que es en Nerval a la vez alucinación pero también y sobre todo fuerza de creación, es el don de ver directamente un universo.

\section{EL ARTE DE NERVAL}

Sus relatos de sueños deben ser leidos como ficción. Cada sueño evoca una visión que hay que tomar como tal; se trata, pues, de un acontecimiento sobrenatural. $Y$ a nosotros nos importa señalar algunos elementos esenciales en los temas fantásticos.

Como sabemos, el autor relata en primera persona las visiones de un personaje durante un período de locura. $Y$ ese yo abarca, aparentemente, dos personas distintas: la del personaje, que vive en el pasado, y que percibe mundos desconocidos y la del narrador, que vive en el presente, y que transcribe las impresiones del primero. Todo el universo nervaliano está marcado por el signo del doble.

El personaje considera sus visiones no como producto de la locura sino como imagen más lúcida del mundo. Es decir, se ubica en lo maravilloso.

Para el narrador, que sabe que esas visiones provienen del sueño o de la locura y no de la realidad, el relato se relaciona con lo extraño. Es el yo enfermo que vivió el drama de la locura, en tanto el yo lúcido del escritor es el que recompone su pasado y sus visiones, los ordena y los recrea.

Esto sucede si leemos a primera vista, pero Nerval recrea la ambigüedad y Aurélia resulta una historia fantástica.

Es que el personaje, a veces cree en su locura, pero nunca llega a la certidumbre: Je compris, en me voyant parmi les aliénés, que tout n'avait été pour moi qu'illusions jusque-la. Toutefois, les promesses que j'attribuais à la déesse Isis me semblaient se réaliser par una série d'épreuves que j'étais destiné á subir.-pág. 76-. (Comprendl, al verme entre los alienados, que hasta entonces todo habla sido para mi más que ilusiones. Sin embargo, las promesas que atribula a la diosa Isis me parecian realizarse por una serie de pruebas que estaba destinado a sufrir.).

Es que lo esencial de lo fantástico se apoya en la incertidumbre. $Y$ el narrador no cree que todo dependa de la ilusión; insiste sobre la verdad de algunos hechos contados: personne n'avait rien entendu. Et cependant, je suis 
encore certain que le cri était réel et que l'air des vivants en avait retenti... -pág. 47/48-. (Nadie habla oldo nada. Y sin embargo, aún estoy seguro de que el grito era real y que el aire del mundo de los vivos había sido estremecido por él.).

Lo fantástico es esencialmente un procedimiento de escritura; la duda se apoya finalmente sobre la significación de las palabras y sobre el lenguaje: je ne sais pourquoi je me sers de ce terme maladie, car jamais pour ce qui me concerne, je ne me suis senti mieux portant. -pág. 4. (No sé por qué me valgo de este término maldito, porque jamás, para lo que me concierne, me sentí en mejor estado de salud.).

En la ambigüedad (que depende también del empleo de dos procedimientos de escritura: el uso del imperfecto y de la modalización) Nerval los utiliza simultáneamente.

Pero, ¿qué significa modalización?: es el empleo de locuciones introductorias que no cambian el sentido de la frase pero modifican la relación entre el sujeto de la enunciación y el enunciado. Ej.: "En el patio cae granizo" y "Tal vez en el patio caiga granizo" se refieren al mismo hecho; pero la segunda señala, además, la incertidumbre del hablante en lo relativo a la verdad de la frase enunciada.

El imperfecto tiene un sentido parecido. "El amaba a Teresa": no preciso si todavia la sigue amando. La continuidad es posible, pero poco probable.

En todo el texto de Aurélla aparecen estos dos procedimientos. Por ejemplo: ...il devenait clair pour moi que les aleux prenaient la forme de certains animaux pour nous visiter sur la terre... -pág. 17-. (...resultaba claro para mi que los antepasados tomasen la forma de ciertos animales para visitarnos sobro la tierra... -).

Si esta locución: "resultaba claro para ml...", no existiera, estariamos dentro de lo maravilloso, lejos de lo habitual, lo cotidiano y real. Gracias a ella, estamos ahora en ambos mundos a la vez. $Y$ como el imperfecto pone distancias entre el personaje y el narrador, no conocemos la posición de este último.

...mes actions, insensées en apparence, étaient soumises à ce que l'on apelle illusion, selon la raison humaine... -pág.11-. (Mis acciones, aparentemente insensatas, estaben sometidas a lo que se llama ilusión, según la razón humana...).

Las acciones insensatas (referencia a lo natural), pero en apariencia (referencia a lo sobrenatural); "estaban sometidas ... a la ilusión" 
(referencia a lo naturat); "... a lo que se llama ilusión" (referencia a lo sobrenatural).

También el imperfecto significa que no es el narrador presente quien piensa así, sino el personaje de antaño.

Y toda la ambigüedad de Aurélia podemos verla en esta frase: ...une série de visions insensées peut-être... -pág. 12-. (... una serie de visiones, tal vez insensatas...).

El narrador se aproxima al personaje y al mismo tiempo que sabe que se trata de locura deja paso a la duda.

En otro ejemplo: ... les récits de ceux qui m'avaient vu ainsi me causaient une sorte d'irritation quand je voyais qu'on attribuait á l'aberration d'esprit les mouvements ou les paroles coincidant avec les diverses phases de ce qui constituait pour moi une série d'événements logiques. -pág. 25/26-. (... los relatos de quienes me habian visto asl me causaban una suerte de irritacion cuando advertía que se atribuían a la aberración del espiritu los movimientos o las palabras que coincidian con las diversas fases de lo que para mi era una serie de acontecimientos lógicos. ).

El narrador toma la tesis del personaje: locura y sueño no son más que una razón superior.

Y en éste: Quoi qu'il en soit, je crois que l'imagination humaine n'a rien inventé qui ne soit vrai, dans ce monde ou dans les autres, et je ne pouvais douter de ce que j'avais vu si distinctement.-pág. 41-. (Sea como fuere, creo que la imaginación humana no ha inventado nada que no sea cierto, en este mundo o en los otros, y no podia dudar de lo que habla visto tan claramente.).

El pasaje empieza en presente y la última proposición está en imperfecto, reintroduce la ambigüedad en la percepción del lector.

Aurélia constituye un ejemplo original y perfecto de la ambigüedad fantástica. Esta ambigüedad gira en torno a la locura. Y sabemos de antemano que el comportamiento del personaje se llama focura. Lo que se trata de saber es si la locura es una razón superior. La vacilación concierne al lenguaje de Nerval; se ubica dentro del nombre, es decir, en su sentido.

Entre los elementos sobrenaturales encontramos el pandeterminismo. ¿Qué significa?: que todo, hasta el encuentro de las diversas series causales (o azar) deben tener su causa, en el sentido pleno del término, aun cuando ésta no sea sino de orden sobrenatural. 
Senalemos algunos ejemplos de pandeterminismo en nuestra obra: (entra en una iglesia) ...J'allal me mettre à genoux aux demierres places du choeur, et je fis glisser de mon doigt une bague d'argent dont le chaton portait gravés ces trois mots arabes: jAllahl |Mohamedl iAlil Aussitót plusiours bougies s'allumèrent dans le choeur... -pág. 69. (me amodillé en los últimos bancos del coro, y me quité del dedo un anillo cuyo engarce tenía tros palabras árabes: |Alá! ¡Mohamedl iAfí!. De inmediato varios cirios se encendieron en el coro... ).

causa.

Aquil no es una mera coincidencia en el tiempo, aqui es una

Un día se pasea por una calle y se desata la tormenta: L'eau s'elevait dans les rues voisines; je descendis en courant la rue Saint-Victor, et, dans lidée d'arreter ce que je croyais l'inondation universelle, je jetai a l'endroit le plus profond l'anneau que j'avais acheté à Saint-Eustache. Vers le méme moment l'orage s'apaisa, et un rayon de soleil commenca a briller. -pág. 73-. (El agua crecia en las calles vecinas; bajé comiendo la calle Saint-Victor y, con la idea de detener lo que crela ser el diluvio universal, arrojé en el lugar más profundo el anillo que habla comprado en Saint- Eustache. En el mismo momento la tormenta se calmó y un rayo de sol empezó a brillar.).

\section{El anillo provoca ol cambio atmosférico.}

Nerval es consciente del significado de estos relatos. y lo expresa así: L'heure de notre naissance, le point de la terre où nous peraissons, le premier geste, le nom, la chambre, et toutes ces consécrations, et tous ces rites qu'on nous impose, tout cela établit une série heureuse ou fatale d'où l'avenir depend tout entier. -pág. 81-. (La hora de nuestro nacimiento, el punto de la tierra en donde aparecemos, el primer gesto, el nombre del cuarto, todas estas consagraciones, esos ritos que nos imponen, todo eso establece una serie feliz o fatal de la cual depende todo porvenir.). On l'a dit justement: rien n'est indifférent, rien n'est impuissant dans l'univers; un atome peut tout dissoudre, jun atome peut tout sauverl - pág. 81/82-. (Con razón se dijo que nada en el universo es indiferente ni impotente; un átomo puede disolverlo todo, jun átomo puede salvarlo todo!).

Vemos que más allá del sentido primero, se puede descubrir un sentido más profundo. Ya lo vimos: la hora en que se nace, el nombre del cuarto, todo cambió de sentido. Asi, uno de los personajes de Aurellia, internado en el sanatorio: J'attribuais un sens mystique aux conversations des gardiens et d celles de mes compagnons.-pág. 78-. (Atribula un sentido mistico a las conversaciones de los guardias y a las de mis compañeros.).

Todos sabemos que las relaciones que establecemos entre los objetos son puramente mentales y no afectan a los objetos entre si. No es 
necesario estar próximo a la locura, como Nerval, para entender esto. Sin embargo, en él estas relaciones se extienden hasta el mundo físico: al tocar el anillo, los cirios se encienden (en el primer ejemplo); al arrojar el anillo, la inundación se detiene ( en el segundo ejemplo).

Es que, en el nivel más abstracto, el pandeterminismo significa que el limite entre lo físico y lo mental, entre la materia y el espiritu, entre la cosa y la palabra, deja de ser cerrado.

metamorfosis.

Veamos ahora otro de los elementos sobrenaturales: la

Hay expresiones corrientes como: ese hombre luchó como un león, o que se hizo el mono o que es un águila. Lo sobrenatural comienza en el instante mismo en que se pasa de las palabras a las cosas supuestamente designadas por ellas. Por consiguiente, las metamorfosis son una transgresión de la separación entre materia y espiritu. Esta metamorfosis concuerda con las perspectivas evolucionistas: Puis les monstres changeaient de forme, et, dépouillant leurs premières peaux, se dressaient plus puissants sous des pattes gigantesques; l'énorme masse de leurs corps brisait les branches et les herbages, et, dans le désordre de la nature, ils se livraient des combats auxquels je prenais part moi-me̊me, car j'avais un corps aussi étrange que les leurs. -pág. 232-. (Después los monstruos cambiaban de forma y, despojándose de su primera piel, se ergulan más poderosos sobre unas patas gigantescas; la masa más enorme de sus cuerpos rompia las ramas y hollaba los hienbajos, y en el desorden de la naturaleza reñian unos combates en los que yo mismo tomaba parte, pues mi cuerpo era tan extraño como los suyos. ).

Otro ejemplo: La dame..., entoura gracieusement de son bras nu une longue tige de rose trémière, puis elle se mit a grandir sous un clair rayon de lumière, de telle sorte que peu à peu le jardin prenait sa forme, et les parterres et les arbres devenajent les rosaces et les festons de ses vêtements;... - pág. 29. (La dama ... rodeó graciosamente con su brazo desnudo el tallo de una makvarrosa, y empezo a crecer bajo un claro de luz; poco a poco, el jardín iba adquiriendo su forma, y los canteros y los árboles se transformaban en los dibujos y festones de sus vestidos... ).

Otras veces, monstruos luchan para despojarse de sus extrafias formas y convertirse en hombres y mujeres: d'autres revêtajent, dans leurs transformations, la figure des bétes sauvages, des poissons et des oisseaux. -pág. 34-. (Otros adoptaban, en sus transformaciones, el aspecto de animales salvajes, de peces y de aves.).

En estos dos temas de los que hemos expuesto: metamorfosis y pandeterminismo, lo que los une es la ruptura del límite entre materia y espiritu. 
El paso del espiritu a la materia se ha vuelto posible, afirma uno de los que estudiaron la obra de Nerval.

$Y$ en este fragmento: Du point où j'etais alors, jo descendis, suivant mon guide, dans une de ces hautes habitations dont les toits rénis présentaient cet aspect étrange. II me semblait que mes pieds s'enfonçaient dans les couches successives des édifices de différents áges. -pág. 23-. (Desde el punto en el que entonces me encontraba, llegué, siguiendo a mi guí, hasta uno de esos altos edificios cuyos techos reunidos presentaban ese extraño aspecto. Me parecía que mis pies se hundian en las capas sucesivas de las construcciones de diferentes edades.).

Repito, en este fragmento el principio citado anteriormente se capta con toda perfección.

La desaparición del límite entre sujeto y objeto, como consecuencia del mismo principio, también sucede en Aurélia: Couché sur un lit de camp, j'entendais que les soldats s'entrenaient d'un inconnu amété comme moi et dont la voix avait retenti dans la méme salle. Par un singulier effet de vibration, il me semblait que cette voix résonnait dans ma poitrine... -pág. 13-. (Acostado sobre un catre, ola que los soldados hablaban acerca de un desconocido, detenido como yo, y cuya voz habia resonado en la misma sala: Por un singular efecto de vibración, me parecía que aquella voz resonaba en mi pecho... ).

Más adelante, el poeta siente que no es necesario que se hablen dos personas para que se comprendan. Cada una puede ser la otra y saber lo que esa otra piensa: II me fit placer prés de lui, et une sorte de communication s'établit entre nous; car je ne puis dire que j'entendisse sa voix; seulement, à mesure que ma pensée se portait sur un point, l'explication m'en devenait claire aussitót, ... pág. 18- (Me pidio -habla de su tío- que me colocara cerca de el, y una suerte de comunicación se establecio entre nosotros; pues no puedo decir que oyese su voz, sino tan sólo que, a medida que mi pensamiento se concentraba en un punto, la explicación de éste me resultaba inmediatamente clara...).

Entonces Nerval comprende que el mundo se comunica de manera directa en esta forma, y asi todos quedan integrados a una red de comunicación generalizada. de la vida cotidiana.

El tiempo y el espacio del mundo fantástico no son iguales a los

El tiempo parece prolongarse para el narrador de Aurélla: Ce fut le signal d'une révolution complète parmi les Esprits qui ne voulurent pes reconnaître les nouveaux possesseurs du monde. Je ne sais combien de mille ans durèrent ces combats qui ensanglantèrent le globe. -pág. 34-. (Aquello fue la señal 
de una revolución completa entre los Espiritus que no quisieron reconocer los nuevos amos del mundo. No sé cuántos miles de años duraron esos combates que ensangrentaron el globo. ).

aventuró.

Nerval recreó así, con palabras, el universo mágico donde él se

\section{LA POESÍA DE NERVAL}

La poesia nervaliana, que se expresa en verso o en prosa (esto último en Aurélla), debe sus resonancias a la extraordinaria experiencia vivida por el autor. Para Nerval el sueño es otra vida a la cual el mundo de los Espiritus se abre para nosotros. La vida real y los recuerdos son transformados por el sueño. La memoria del poeta se vuelve, de alguna manera, intemporal. El destino del poeta figura el del alma humana, culpable y castigada, pero esperando la redención al término de una serie de pruebas.

Una misteriosa correspondencia se establece entre el mundo familiar y el mundo irreal del sueño.

Así, todo toma un doble aspecto: una flor, un beso dado a una joven, se vuelven signo y símbolo.

Se entiende, entonces, todo to que la poesía simbolista y después surrealista deberá a Nerval. Pero el simbolismo y el surrealismo de nuestro poeta son absolutamente auténticos: la visión del más allá en él no es jamás, un artificio literario.

Prefirió siempre las seducciones especiales del sueño, de la fantasia, a las tristes realidades de la vida. Le gusta resucitar leyendas del Valois o del folklore germánico. Se complace con la atmósfera de fiestas de disfraces con vestidos antiguos porque le dan la ilusión de un siglo desaparecido.

Modela en la imaginación la forma inmaterial de su ideal femenino. Evoca los paises lejanos que visitó y transfigura los paisajes familiares de su infancia por la magia del recuerdo.

Busca correspondencia entre el sueño y la vida: en Aurélia afirma que el sueño ayuda a penetrar el sentido escondido de la aventura terrestre. Y la poesia fue el medio que utilizó para fijar las imágenes de sus fantasias. 


\section{EL LECTOR Y AURÉLIA}

Lo que golpea a un lector atento de la obra es el carácter muy construido, elaborado de estos suehos, muy diferente de las alucinaciones del delirio.

Lo que golpea, también, es la voluntad de organizar el conjunto de una progresión que responde a una experiencia mistica: primera aproximación a la verdad; noche de los sentidos o muerte; por último, tercer tiempo: de la resurrección.

Es esto también, una necesidad del relato y en particular del cuento. En un primer momento el héroe está mostrado como viviendo en una situación de equilibrio (la vida del estudiante bohemio); después este equilibrio se cuestiona y finalmente está completamente trastornado por la locura. Por último, el héroe vuelve a encontrar un estado de equilibrio, pero se trata de un equilibrio radicalmente diferente: Nerval ha atravesado, victorioso al final, el Aqueronte, el río de las iniciaciones. 


\section{BIBLIOGRAFÍA}

Nerval, G. de, Oeuvres, Class. Garnier, 2 vol., 1967.

Castex, P.G., Le Conte fantastique en France, Paris, Corti, 1951.

Piaget, J., Six études de psychologie, Paris, Gonthier, 1967.

Todorov, T., Introduction à la littérature fantastique, Paris, De. du Seuil, 1980.

Vaz, L., L'Art el la Littérature fantastique, Paris, P.U.F., 1960. 